4. Ljunggren, M. (1994). The Russian Mephisto. A Study of the Life and Work of Emilii Medtner. Stockholm [in English].

5. Martyn, B. (1995). Nicolas Medtner. His Life and Music. London: Routledge [in English].

6. Matich, O. (2005). Erotic utopia. The decadent imagination in Russia's fin-de-siucle. Madison: University of Wisconsin Press [in English].

7. Metner, E. (1912). Modernizm i muzyka [Modernism and music]. Moscow [in Russian].

8. Metner, N. (1935). Muza i moda [Muse and fashion]. Paris [in Russian].

9. Metner, N. (1973). Pis'ma [Letters] / ed. by Z. Apetyan. Moscow: Sovetskiy kompozitor [in Russian].

УДК $781+78.01 / .072$

DOI https://doi.org/10.31723/2524-0447-2019-29-2-2

Марина Романовна Черкашина-Губаренко

ORCID: 0000-0002-7347-4309

доктор искусствоведения, профессор

Национальной музыкальной академии Украины имени П. И. Чайковского, академик

Национальной академии искусств Украины gubaresha@ukr.net

\title{
НИКОЛАЙ И ЭМИЛИЙ МЕТНЕРЫ, РИХАРД ВАГНЕР И КУЛЬТУРА РУССКОГО СЕРЕБРЯНОГО ВЕКА
}

Цель статьи - представить освоение идей и восприятие музыкальных новаций Вагнера русским обществом как многоэтапный и многоуровневый процесс, имеющий свои важные вехи. Методология работы определяется историографическим и эстетическим стилевым подходами, реализованными в русле музыковедческого систематического стилевого анализа. Научная новизна статьи обусловлена параллельным охватом и сведением в общий динамический ряд разных исследовательских аспектов данной темы, также выявлением не лежащих на поверхности связей с фигурой Вагнера и с его личностью семьи Метнеров. Обнаруживается, что семейная история так или иначе повлияла на отношение к Вагнеру как старшего Эмилия Метнера, так и его

(C) Черкашина-Губаренко М. Р., 2019 
младшего брата, композитора и пианиста Николая Метнера. Изучаются непосредственные и опосредованные соприкосновения с вагнеровским искусством творчества Николая Метнера, который, наряду с Рахманиновым и Скрябиным вошел в историю музыкальной культуры как знаковая фигура переходного Серебряного века. Доказывается, ито особое отношение Метнеров к имени и личности Вагнера было связано с одной из семейных саг их собственного рода по материнской линии Гебхардов-Гедике. Выводы. Вагнеровское отношение к искусству и его настойчиво повторяющееся утверждение, что оно внутренне едино, оказались особенно близки ХХ веку. Важно отметить, что такое отношение вступало в противоречие с традиционными методами художественного образования, господствующими в профессиональных учебных заведениях. Процесс освоения идей и музыкальных произведений Вагнера $\kappa$ началу XX века уже прошел несколько стадий; композиторы новой генерации стремились освобождаться от плена прямых вагнеровских влияний и трансформировать их в соответствии с собственными национальными задачами; прежняя полемичность оценок музыки Вагнера сменилась углублённым изучением его творческих принципов.

Ключевые слова: вагнеровское искусство, вагнеровская традиция, имя Вагнера, русская культура Серебряного века, Николай и Эмилий Метнеры.

Cherkashin-Gubarenko Maryna Romanovna, Doctor of Arts, Professor of the Ukrainian National Tchaikovsky Academy of Music, Academician of the National Academy of Arts of Ukraine

Nicholas and Emily Medtners, Richard Wagner and the Culture of the Russian Silver Age

The purpose of the article is to present the development of ideas and perception of the musical innovations of Wagner by Russian society as a multi-stage and multi-level process, which has its important milestones. The methodology of work is due to the historiographic and aesthetic stylistic approaches implemented in line with musicological systematic style analysis. The scientific novelty of the article is determined by the parallel coverage and reduction to the whole dynamic of various research aspects of the topic, as well as the identification of those links with the figure of Wagner and his personality of the Medtner's family, which do not lie on the surface. It turns out that the family history in one way or another influenced Wagner's attitude to both the elder Emily Medtner and his younger brother, composer and pianist Nicholas Medtner. Direct and indirect encounters with the Wagnerian art of Nikolai Medtner, who, along with Rachmaninov and Skryabin, are included in the history of musical culture as a landmark figure of the transitional Silver Age. It is proved that Medtner's special attitude to the name and personality of Wagner was related to one of the family sagas of their own kind along the Gebhard-Gedike maternal line. Conclusions. Wagner's attitude to art and his persistently repeated claim that it is internally the only one, was particularly close to the twentieth century. It is important to note that this attitude conflicted with traditional methods of art education that prevailed in 
professional art schools. The process of mastering the ideas and musical works of Wagner by the early twentieth century had already passed several stages. Composers of the new generation sought to free themselves from the captivity of direct Wagner influences and to transform them in accordance with their own national tasks, the former polemicality of the evaluations of Wagner's music was replaced by an in-depth study of his creative principles.

Key words: Wagnerian art, Wagnerian tradition, Wagner name, Russian culture of the Silver Age, Nicholas and Emily Medtners.

Черкашина-Губаренко Марина Романівна, доктор мистецтвознавства, професор Національної музичної академії України імені П.І. Чайковського, академік Національної академії мистецтв України

\section{Микола та Емілій Метнери, Ріхард Вагнер і культура російської Срібної доби}

Мета статmі- представити освоєння ідей і сприйняття музичних новацій Вагнера російським суспільством як багатоетапний $і$ багаторівневий процес, що має свої важливі віхи. Методологія роботи зумовлена історіографічним і естетичним стильовим підходами, реалізованими в руслі музикознавчого систематичного стильового аналізу. Наукова новизна статті визначається паралельним охопленням та зведенням до загального динамічного ряду різних дослідницьких аспектів даної теми, також виявленням тих зв'язків sз постаттю Вагнера та з його особистістю родини Метнера, що не лежсть на поверхні. Виявляється, що сімейна історія так чи інакше вплинула на ставлення до Вагнера як старшого Емілія Метнера, так і його молодшого брата, композитора і піаніста Миколи Метнера. Вивчаються безпосередні та опосередковані зіткнення з вагнерівським мистеитвом творчості Миколи Метнера, який, поряд sз Рахманіновим і Скрябіним, увійшов до історії музичної культури як знакова постать перехідного Срібного століття. Доводиться, що особливе ставлення Метнера до імені та особистості Вагнера було пов'язаним з однією зз сімейних саг їх власного роду по материнській лінії Гебхард-Гедіке. Висновки. Вагнерівське ставлення до мистецтва та його настійливо повторюване твердження, що воно внутрішньо єдине, виявилося особливо близьким ХХ століттю. Важливо відзначити, що дане відношення вступало у протиріччя з традиційними методами художньої освіти, що панували у професійних мистеиьких навчальних закладах. Процес освоєння ідей $і$ музичних творів Вагнера до початку ХХ століття вже пройшов декілька стадій. Композитори нової генерації прагнули звільнятися від полону прямих вагнерівських впливів та трансформувати їх відповідно до власних національних завдань, колишня полемічність оцінок музики Вагнера змінилася поглибленим вивченням його творчих принципів.

Ключові слова: вагнерівське мистецтво, вагнерівська традиція, ім'я Вагнера, російська культура Срібного століття, Микола та Емілій Метнери. 
Актуальность исследования. Хотя тема «Рихард Вагнер и русская культура», казалось бы, достаточно разработана и в конкретно музыковедческом, и в более широком культурологическом аспектах [3; 7; 8; 9], ее все же никак нельзя назвать полностью исчерпанной. Возникает необходимость представить освоение идей и восприятие музыкальных новаций Вагнера русским обществом как многоэтапный и многоуровневый процесс, имеющий свои важные вехи. После первых сведений, появлявшихся в печати, и новостей, поступавших в основном из-за рубежа, к знаковым событиям относятся концерты Вагнера в 1863 году в Петербурге и Москве, которые были проведены не без деятельного участия Александра Серова - русского поклонника творчества немецкого гения. Затем нужно назвать первые постановки на русских сценах вагнеровских опер и реакцию на них. Важным событием стало присутствие представителей русского музыкального мира на первом вагнеровском фестивале в Байройте в 1876 году и их оценки увиденного и услышанного. За этим последовал захвативший и Россию нарастающий интерес к Вагнеру в разных странах, который развивался уже после смерти композитора. На русской почве этому способствовало знакомство с тетралогией «Кольцо нибелунга» в исполнении приезжих трупп, ее адаптация русскими артистами и музыкантами. Параллельно с этим изучаются и комментируются теоретические и эстетические работы Вагнера, с вагнеровской темой начинает переплетаться волнующий сюжет взаимоотношений Вагнера и Ницше, совпадающий с волной увлечения деятелями русской культуры Серебряного века фигурой Ницше и его философией.

Цель статьи - представить освоение идей и восприятие музыкальных новаций Вагнера русским обществом как многоэтапный и многоуровневый процесс, имеющий свои важные вехи. Новым в предлагаемой статье являются не только параллельный охват и сведение в общий динамический ряд разных исследовательских аспектов данной темы, но также выявление не лежащих на поверхности связей с фигурой Вагнера и с его личностью семьи Метнеров. Семейная история так или иначе повлияла на отношение к Вагнеру как старшего Эмилия Метнера, так и его младшего брата, композитора и пианиста Николая Метнера. Казалось бы, трудно найти непосредственные соприкосновения с вагнеровским 
искусством творчества этого русского композитора, который наряду с Рахманиновым и Скрябины вошел историю как знаковая фигура данной эпохи. Вряд ли в этом смысле можно считать решающим фактором немецкое его происхождение. Николай Метнер, всю жизнь представлявший себя как подлинно русского художника, никогда не писал опер, не проявлял особенного интереса к музыкальному театру как таковому. Не писал он и симфонической музыки, по отношению к которой более всего можно было бы говорить о воздействии веймарской вагнеро-листовской школы. Тем не менее, и он не прошел мимо Вагнера, а в какой-то момент нашел в его взглядах созвучность с собственными убеждениями.

Основное содержание исследования. В воспоминаниях о Метнере Владимира Ивановича Поля, композитора, пианиста и музыкально-общественного деятеля, создателя русской консерватории в Париже приведен любопытный эпизод, который позволяет оценить отношение русского Мастера к композиторскому таланту Рихарда Вагнера. Поль привел в своем письме к Метнеру слова самого Вагнера, обнаруженные в воспоминаниях его французской музы времен создания «Парсифаля», талантливой поэтессы и новеллистки Джудит Готье. Когда Джудит попросила Вагнера оценить присланную ею партитуру некоего модного молодого композитора передовых взглядов, просмотрев ее, Вагнер ответил: «Иногда я думаю, как много музыки существует на свете и как невелико число музыкантов, которых я мог бы по-настоящему полюбить из-за нескольких сочинений, содержащих для меня все, что я понимаю под словом музыка... Даже дерзновения в области оркестровки, о которых Вы мне говорите, меня огорчают. В начинаниях всех этих молодых людей я не вижу ничего, кроме дерзновений в инструментовке или гармонии, но никак не в мелодии» [13, с. 318]. Николай Метнер вполне мог бы подписаться под этим вагнеровским признанием. Поблагодарив своего корреспондента за присланные высказывания не только Вагнера, но и Римского-Корсакова, Метнер добавил свой комментарий: «...Необычайно ценно, что такие передовые мастера во всеоружии инструментовки придавали наибольшее значение мелодии - душе музыки, без которой вся остальная плоть не имеет никакой цены» [13, с. 104].

Из двух братьев Метнеров с Вагнером большую близость, без сомнения, ощущал Эмилий Карлович. Эмилий Метнер 
был самым тесным образом связанный с культурой русского Серебряного века и с русским символизмом, которые невозможно себе представить без большой роли «вагнеровского сюжета». Как дань увлечения Вагнером появился взятый Эмилем Карловичем литературный псевдоним Вольфинг, которым он подписывает свои статьи. Он произошел из ссылки на род Вёльзунгов, произведенный на свет героем вагнеровской тетралогии богом Вотаном и включавший его детей Зигмунда и Зиглинду, а также внука Зигфрида.

Особое отношение Метнеров к имени и личности Вагнера было связано с одной из семейных саг их собственного рода по материнской линии Гебхардов-Гедике. В руках Эмилия Метнера оказался семейный реликт, переданный ему бабушкой, первое немецкое издание известной работы Вагнера «Das Kunstwerk der Zukunft» («Произведение искусства будущего»). Она вышла из печати в 1850 году в Лейпциге в издательстве Отто Виганда и имела посвящение Фридриху Фейербаху, которое Вагнер впоследствии снял. Эта книга находилась среди других ценных книг и письменных документов, таких, например, как первое издание 1808 года «Фауста» Гете, в личной библиотеке прадеда Метнеров по материнской линии Фридриха Гебхарда. Происходивший из Тюрингии, в юности Гебхард пошел по линии семейной традиции и стал богословом. Затем он увлекся театром и сбежал из дома с театральной труппой. Актерскую карьеру, начатую в Риге, продолжил в Петербурге. Здесь он выступал вместе с женой, урожденной фон Штейн, одновременно в немецких драматической и оперной труппах. Выйдя на пенсию и поселившись в Москве, Фридрих Гебхард вел интеллектуальные занятия и переписывался с видными деятелями культуры. Среди его корреспондентов значился Гете, с которым он был знаком лично, а также Вагнер. Как пишет Эмилий Метнер, экземпляр вагнеровского труда, полученный им от бабушки Полины Федоровны Гедике, стал первым проводником в мир вагнеровских мыслей об идеале музыкальной драмы, противопоставляемой опере старого образца. В этой вагнеровской работе, написанной в октябре-ноябре 1849 года в Цюрихе, впервые были последовательно изложены взгляды Вагнера на синтез музыки и драмы в целостном произведении сценического искусства будущего. Говоря об интересе к ней своего прадеда, Э. Метнер подчеркивал важность того факта, что «старый гетеанец, 
актер, воспитанный на Шекспире и Шиллере, певец, уже в юности сроднившийся с Моцартом и Россини, с первого же взгляда узрел в юном преобразователе искусства несомненную гениальность» ${ }^{1}$.

Когда Рихард Вагнер умер в Венеции 13 февраля 1883 года, маленькому Николаю Метнеру едва исполнилось три года, а его старшему брату Эмилию было всего одиннадцать лет. К этому времени в России процесс освоения идей и музыкальных произведений Вагнера уже прошел несколько стадий. Знакомство с именем немецкого композитора произошло еще до того, как стала звучать его музыка. Сам он тогда только искал собственный путь и пробовал свои силы как критик, находясь в бедственном положении в Париже, где тщетно надеялся покорить главную европейскую оперную сцену, парижскую Гранд опера. В России о нем вначале узнали, когда статья «Об увертюре», напечатанная в 1841 году в Парижской «Gazette musicale», появилась в русском переводе ${ }^{2}$ В русскую прессу вскоре стали приходить сведенья об успешной премьере в Дрездене оперы «Риенци». Но с главными дрезденскими операми 1840-х годов, которые имели для композитора программное значение, русская публика познакомится далеко не сразу. Вначале куда более известным он станет как идеолог и теоретик, критиковавший современное состояние искусства и ратовавший за его решительное обновление.

Знакомство с теоретическими работами Вагнера стало благодарной почвой для повышенного интереса, который вызвал приезд Вагнера в Россию в 1863 году. Эту дату можно назвать началом второго этапа русского «вагнеровского сюжета». K тому времени в России уже был свой страстный вагнерист, статьи и выступления которого готовили публику ко встрече с музыкой нового немецкого гения. Композитор и популярный критик Александр Серов, как и некоторые другие его современники, сначала открыл для себя Вагнера-теоретика. Но с конца 1850-х годов он стал самым преданным

${ }^{1}$ Письмо Э. К. Метнера - П. Д. Эттингеру от 27 сентября 1921 года, Цюрих. См.: [11, с. 297].

2 В новом русском переводе А. В. Михайлова она была вновь напечатана в 1974 году в сборнике Московский государственной консерватории имени П.И. Чайковского «Рихард Вагнер. Статьи и материалы». Москва : Музыка, 1974, с. 5-18. 
русским вагнеристом, постоянно освещая в собственных статьях взгляды Вагнера на оперную реформу, знакомя русских читателей с его произведениями. Как напишет он сам в письме к М.П. Анастасьевой, огорчаясь по поводу ее нелюбви к Вагнеру, «с своей стороны, я только и брежу Вагнером, его играю, изучаю, об нем читаю, пишу, говорю, проповедую. Я горжусь тем, что могу быть его апостолом в России» ${ }^{3}$.

Во время своих заграничных поездок 1858 и 1859 годов Серов познакомился с Вагнером лично, вступил с ним в переписку ${ }^{4}$. Начало дружеских контактов Серова с Вагнером было особенно трудным периодом в жизни немецкого композитора. Потерпели крах его парижские планы. Тщетными оказались надежды устроить там постоянно действующий Немецкий оперный театр. Со скандальным провалом прошли премьерные постановки «Тангейзера» на сцене Гранд Опера. Не ясной оставалась судьба завершенной еще пять лет назад партитуры «Тристана и Изольды». В Россию Вагнера привела не в последнюю очередь материальная нужда. На его концертах, которые прошли в Петербурге и в Москве, присутствовали самые известные представители русской художественной среды того времени. Безусловное признание получил талант Вагнера-дирижера [7]. Тактический ход оказался верным. Риск знакомства с непривычной музыкой был куда меньшим при концертном исполнении симфонических эпизодов и оперных фрагментов. Облегчила восприятие этой музыки темпераментная авторская интерпретация. Благодаря вагнеровским концертам 1863 года в России начла формироваться более обширная группа приверженцев его искусства.

Вскоре после этого настало время открыть дорогу на сцены операм Вагнера. Первой его оперой, которую увидела русская публика, был «Лоэнгрин». Это произошло в 1868 году, через 18 лет после проведенной под руководством Ф. Листа премьеры в Веймаре. Обратим внимание на знаменательное совпадение. Именно этот год был ознаменован знакомством с Рихардом Вагнером юного Фридриха Ницше и началом их длительных дружеских отношений, впоследствии

3 Из письма А.Н. Серова к Марии Павловне Анасмтасьевой 7/19 апреля 1859 г. «Русская старина», 1877. Т. 20, с. 534.

4 Письма Р Вагнера А. Серову напечатаны в русском переводе в книге Е. М. Браудо [3]. Более подробно тема «Серов и Рихард Вагнер» освещена также в моей монографии [18]. 
ставших столь непростыми и драматическими. Об этом стоит вспомнить, поскольку в процессе формирования образа «русского Вагнера» тень Ницше так или иначе будет всегда присутствовать. Русское ницшеанство создавало с вагнеровским сюжетом достаточно сложные перекрещивания и переплетения. Показательно в этом плане письмо Эмилия Метнера к Борису Бугаеву (Андрею Белому) от 31 января-3 февраля 1903 года. Признаваясь, что музыкальную драму Вагнера он пока еще не достаточно хорошо знает, Эмилий Метнер тем не менее сопоставляет имена Вагнера и Ницше: «Как Ницше - явление, возможное именно после освободительной строгости Канта (как в музыке строгий стиль предшествует свободному), - философ, поэт, музыкант и Вагнер - музыкант, поэт, философ вновь комбинируют, соединяют, символизируют то, что раньше «смешивалось», и что после Канта его разумом обособленное друг от друга способно стало к сочетанию не «смешанному» [1].

Но вернемся к «Лоэнгрину». Отзывы на премьеру оказались разными. Откровенно негативной была реакция представителей петербургской «новой композиторской школы». Считается, что частично такое неприятие могло быть вызвано качеством исполнения. Константин Лядов, который дирижировал премьерой, завершал свою дирижерскую карьеру и не сильно вдохновился новой для него партитурой, что сказалось и на восприятии публики. Уже через год Мариинский театр возглавил талантливый молодой капельмейстер Эдуард Направник, которому суждено было стать выдающимся русским интерпретатором опер Вагнера. В 1874 году, через шесть лет после «Лоэнгрина», под его руководством был поставлен «Тангейзер». Спектакль вызвал четкое разделение публики на поклонников и врагов композитора.

Между тем в жизни самого Вагнера к тому моменту произошел судьбоносный переворот. В 1864 году преданного поклонника и покровителя на многие годы он нашел в лице вступившего на трон юного баварского короля Людвига II. Одним из первых художественных результатов их «звездной дружбы» стала постановка на сцене Королевского оперного театра в Мюнхене оперы «Тристан и Изольда». При повторном исполнении оперы в 1869 году по приглашению композитора Александр Серов и его жена Валентина присутствовали на этом спектакле. По словам Валентины, «после первых 
звуков я была буквально уничтожена от силы впечатления. Это выхватывание человека из прозаической сферы именно туда, куда заблаговолит Рихард - это его сила, его гений» [14, с. 1695]. Сам же Александр Серов характеризует «Тристана и Изольду» как «высшую, полнейшую в свете музыкальную трагедию, перед которой и «Тангейзер», и «Лоэнгрин» только приготовительные ступени с яркими недостатками, которых в «Тристане» и помину нет». И тут же добавляет: «Я поистине горжусь, что я современник этого колосса, дружески знаком с ним. Его дружба (искренняя) возвышает меня в собственных глазах» [14, с. 1697].

Уже после внезапной смерти Серова в 1971 году, на которую Вагнер откликнулся теплым письмом-соболезнованием, произошло знаковое культурно-исторического событие, после которого фигура Вагнера и вся его деятельность приобрели совершенно новый масштаб. Речь идет о первом организованном Вагнером в августе 1876 года оперном фестивале в Байройте, на котором впервые была исполнена тетралогия «Кольцо нибелунга». Среди именитых гостей фестиваля, прибывших со всего мира, были и представители русской музыкальной общественности, композиторы Н. Рубенштейн, П. Чайковский, Ц. Кюи, музыкальные критики Г. Ларош и А. Финдейзен. Их подробные отчеты о фестивале появились в русской прессе. П. Чайковский, к тому времени уже автор трех завершенных опер и трех симфоний, представлял популярную массовую газету «Московские ведомости». Показательно, что уже в первой из пяти газетных статей, носящих красноречивое название «Байрейтские музыкальные торжества», П. Чайковский охарактеризовал вагнеровский фестиваль как событие, «которому суждено отметить собою одну из интереснейших эпох истории искусства» [17; 20].

Появление тетралогии и ее постановка в особых условиях специального фестивального театра действительно стало событием эпохальным. Резонанс, который вызвала данная культурная акция, как бы открыл для всех деятелей искусства дорогу дерзаний и повысил многократно их самооценку. Одинокий романтический гений, находившийся в оппозиции к обществу торгашей, политиков и обывателей, выходил из своего уединения на большие просторы и превращался в лицо публичное, заставив признать всечеловеческую значимость созданного им творения. Байройт как место палом- 
ничества, уникальный «театр на зеленом холме» стали символами независимости художника, диктующего свою волю. И это несмотря на то, что сам проект, как бы мы сказали сегодня, находился под патронатом баварского короля, а композитор принимал его покровительство, не утрачивая достоинства. Я не сомневаюсь, что пример Вагнера должен был в течение многих лет вдохновлять поклонника его искусства Сергея Дягилева, когда в постоянных поисках средств на новые балетные постановки и на всю деятельность созданного им Русского балета он обращался к богатым аристократам и состоятельным любителям из разных стран. Ведь не случайно Дягилев запланировал по вагнеровскому образцу собственную смерть в любимой им Венеции.

Премьера «Кольца нибелунга» стала переломным моментом также в отношениях Вагнера и Ницше. В Байройт его молодой друг поехал неохотно и только из-за уговоров друзей. И хотя он отдал дань этим уже угасающим отношениям в третьем письме из «Несвоевременных размышлений», озаглавленном «Вагнер в Байройте», по тону этого репортажа с места событий и некоторым оговоркам уже можно было предощутить вскоре разразившийся кризис (см. об этом: [21]). Наблюдая Вагнера во время фестиваля, Ницше увидел в нем актера, работающего на публику. Вагнер, которого он любил и знал, с этих пор для него навсегда потерян. Вскоре из пути расходятся окончательно. Выход в свет в 1878 году книги Ницше «Человеческое, слишком человеческое» вызывает резкое неприятие Вагнера. Не остаются незамеченными и публичные нападки по адресу бывшего друга, хотя и без упоминания его имени.

Туринское письмо Ф. Ницше под названием «Казус Вагнер» появится через пять лет после смерти автора «Парсифаля». Сбрасывая с пьедестала бывшего кумира, Ницше рисует его как лицедея-искусителя, а его искусство называет декадентским, свидетельством глубокого кризиса всей европейской культуры. Вскоре после появления этого письма в России произошло знакомство с тетралогией «Кольцо нибелунга». Пражский антрепренёр Анджело Нойман в 1889 году представил весь цикл в Петербурге в исполнении передвижной немецкой труппы. Вместе с немецкими солистами выступал оркестр и хор Мариинского театра, дирижировал спектаклями Карл Мук (1859-1940), в тот период главный дирижер 
немецкой оперы в Праге. Восхищенный искусством Вагнера, Александр Бенуа, русский художник, друг и соратник Сергея Дягилева и впоследствии сотрудник Русского балета в Париже, эту постановку раскритиковал. У него уже в то время стал формироваться собственный взгляд на сценическую интерпретацию образов тетралогии.

На следующий год после приезда Ноймана интернациональная оперная труппа Георга Парадиза показала в Петербурге «Лоэнгрина» и «Тангейзера» под управлением австрийского дирижера вагнеровского круга Ганса Рихтера (1843-1916). Впервые прозвучали тогда в России также «Нюрнбергские мейстерзингеры», «Тристан и Изольда» и «Летучий голландец». Год спустя «Тристан и Изольда» появляется уже в интерпретации русских певцов, среди которых выделяется новая примадонна Фелия Литвин. Более основательное знакомство с произведениями Вагнера отражается и на содержании критических оценок в русской прессе. С 1905 года Вагнера стали регулярно ставить и исполнять также в Москве. Постановка на русских сценах опер Вагнера способствовала заметному росту исполнительского мастерства русских певцов и оркестровых музыкантов.

Показательно, что в этот же период начинается в России увлечение произведениями Ницше, которое неуклонно возрастает с последнего десятилетия XIX до начальной декады XX века. Важную роль в истолковании философских взглядов немецкого мыслителя сыграла статья В. Преображенского «Фридрих Ницше. Критика морали альтруизма», опубликованная в 15 номере журнала «Вопросы философии и психологии» за 1892 год. А в 1898 и 1899 годах появляются в печати русские переводы таких произведений Ницше, как «Так говорит Заратустра» и «Рождение трагедии из духа музыки» 5 . В то время как Вагнера начинают оценивать сквозь призму противоречивой позиции Ницше, взгляды самого Ницше получают на русской почве свою корректировку не без воздействия духовного лидера молодого русского поколения Владимира Соловьева (1853-1900). Религиозный философ, поэт и публицист, Владимир Сергеевич Соловьев стоял у истоков русского духовного возрождения и оказал влияние на поэтов-символистов. Особенно это касалось его «софиологии»-представлений

$\overline{5}$ Подробнее об этом пишет в своей диссертации Корж Юлия Викторовна [10]. 
про Софию - Премудрость Божью, Вечную женственность и душу мира, мистическое космическое существо и неотъемлемую часть замысла Бога про мир. В одной из последних своих работ, носящих название «Идея сверхчеловека», В. Соловьев выделяет положительную сторону отрицательных суждений Ницше, - ту истину, которая проступает за заблуждениями ницшеанства. Он подчеркивает, что человеку по его двойной, духовно-телесной природе свойственно стремление к бесконечному самосовершенствованию и к достижению идеала сверхчеловека как потенциального победителя главного зла-смерти. Он упоминает в связи с этим о «первенце среди мертвых», победившем смерть богочеловеке Иисусе Христе. По его словам, по такому же сверхчеловеческому пути шли и идут многие подвижники [15].

Критика Ницше, направленная в адрес Вагнера, парадоксальным образом лишь увеличила общий интерес к его личности и к взглядам на культуру в ее общественной функции. Об особенностях восприятия Вагнера деятелями русского Серебряного века так пишут в своей статье И.В. Кондаков и Ю.В. Корж: «Прививка» вагнеровских идей к стволу русской культуры, коренящаяся в богословско-культурологических исканиях Хомякова и Соловьева, нашла своеобразное отражение в трактовке Вагнера представителями Серебряного века» [9, с. 160]. По их словам, фигура Вагнера оказывалась в такой трактовке далека от реальности и представляла собой «свободную фантазию русских символистов на реального Вагнера, равно как и Ницше, Владимира Соловьева, ранних славянофилов и французских символистов» [9, с. 163]. Вагнер интересовал их в первую очередь не столько как гениальный музыкант-новатор, сколько как теоретик искусства и философ культуры.

Если посмотреть общеевропейский контекст, то становится очевидным, что в последние десятилетия XIX, в начале XX века число сторонников Вагнера как композитора и мыслителя возрастало в разных странах. Он был зачислен в разряд великих классиков масштаба И. С. Баха, В. Гете и Л. Бетховена. Так, заметное влияние идей и творчества Вагнера наблюдается в этот период в среде итальянских композиторов, представлявших новую «молодую школу». Еще в годы студенчества в складчину с Дж. Пуччини П. Масканьи приобрел партитуру «Парсифаля». А. Бойто переводил на итальянский язык оперы «Риенци» и «Тристан и Изольда», а также тексты вокального 
цикла «Пять стихотворений Матильды Везендонк». Дж. Пуччини посетил постановку «Нюрнбергских майстерзингеров», после чего Джулио Рикорди поручил ему подготовить редакцию партитуры для запланированного спектакля в театре Ла Скала. Именно в этот период Дж. Пуччини работал над своей первой зрелой оперой «Манон Леско». Интересны вагнеровские отголоски в творческих планах Р. Леонкавалло. Задумав оперную трилогию «Сумерки» на сюжет из истории итальянского Ренессанса, он так комментировал свой замысел: «Верный принципам байройтского гения, я пытался создать национальную поэму и, соответственно, хотел, чтобы итальянское постоянно чувствовалось в музыке поэмы» [5; 4].

В то время как композиторы новой генерации стремились освобождаться от плена прямых вагнеровских влияний и трансформировать их в соответствии с собственными национальными задачами, прежняя полемичность оценок музыки Вагнера сменилась углублённым изучением его творческих принципов. Основателями журнала "La Revue wagnerienne", который начал выходить во Франции, были Теодор де Визева (1863-1917) и Эдуард Дюжарден (фр. Йdouard Dujardin, 18611949). Последний приобрел известность как поэт, прозаик, драматург и критик, а также один из основателей символистской драматургии. После триумфа «Парсифаля» в новом журнале объединяются все лидеры французского символизма. В проекте журнала Е. Дюжарден называет наряду с писателями и художниками композиторов Е. Шабрие, Е. Шоссона, В. д'Энди П. Дюка. Еще один фантастический приверженец Вагнера писатель-оккультист Сар Пелладин (1858-1918, настоящее имя Еме Пелладан) задумывает под влиянием «Парсифаля» создание трех орденов: «Роза и Крест», «Храм», «Грааль». Он открыл известный в Париже «символистский Салон ордена Розы и католического Христа» и появлялся на его заседаниях в костюмах вагнеровских героев. В этом салоне выставляли свои картины художники-символисты Гюстав Моро и Пьер Пюви де Шаван. В 1885 году в "La Revue wagnerienne" эссе о Вагнере публикует Стефан Маларме. Высказывая свое отношение к синтезу искусств, он упрекает Вагнера в том, что он игнорировал в своих размышлениях танец. Не удовлетворяет С. Маларме также стиль вагнеровских постановок в Байройте. Можно вспомнить еще одного французского приверженца Вагнера Эдуарда Шюре (1841-1929). Идею синтеза искусств он 
развивал в своей работе 1875 года «Музыкальная драма», в которой утверждал, что идеалом может стать не собственно музыкальная, а словесная драма с включением музыки и, подобно С. Маларме, считал необходимым прибавить к драме и музыке танец.

В это же время арена споров о будущих путях музыкального искусства переместилась на оценки новых авангардных тенденций. В России предметом дискуссий становились произведения французских, немецких и русских композиторов нового поколения, в частности, тех, которые звучали в Петербурге на Вечерах современной музыки. Возглавлявшие эти собрания музыкальные критики Вальтер Нувель и Альфред Нурок, также, как и Сергей Дягилев, были поклонниками Вагнера.

В сезоне 1900-1901 года на сцене Мариинского театра в исполнении русской труппы под управлением Э. Направника ставится «Валькирия», в феврале 1903 года - «Зигфрид», в сентябре того же года к ним прибавляется «Гибель богов». К 1905 году был осуществлен весь вагнеровский цикл и выпущены абонементы, позволявшие его охватить в целом. Об огромной роли этих абонементных циклов в художественной жизни Петербурга, в то время насыщенной яркими событиями, вспоминал в автобиографических заметках композитор и музыковед-исследователь Борис Асафьев. Он назвал эти события «лучшей школой музыкального восприятия, не только как слухового внимания, а как процесса художественно-интеллектуального. ...Что делалось в антрактах в верхних ярусах театра: философские и музыковедческие споры, обсуждения партитур, критика и восторги по адресу исполнителей, диалоги итальянистов-меломанов и жрецов вагнеризма, музыкально-профессиональные кружковые дискуссии, фейерверк мыслей писателей и историков, поэтов и художников...» [2, с. 442].

В 1909 году, как раз в период большого резонанса вагнеровских постановок Мариинского театра, из печати выходит русский перевод книги Э. Шюре «Рихард Вагнер и его музыкальная драма» [22, с. 312]. В предисловии к книге ее редактор А. Ф. Каль сетует на незначительное количество имеющейся русской литературы о Вагнере, в то время как, по его словам, «Вагнер глубоко пустил в русской культуре свои корни, и интерес к его творчеству не менее интенсивен, чем в Западной Европе» [22, с. 9].

Вагнеровское отношение к искусству и его настойчиво повторяющееся утверждение, что оно внутренне едино, 
оказались особенно близки XX веку. Важно отметить, что такое отношение вступало в противоречие с традиционными методами художественного образования, господствующими в профессиональных учебных заведениях. В них обучение искусству понималось как овладение ремеслом. Так учили студентов в Петербургской консерватории. Об этом Борис Асафьев написал в своих воспоминаниях. Он пришёл в консерваторию после окончания начального курса Петербургского университета. По сравнению с университетом консерватория показалась ему «то вновь гимназией, то словно бы монастырём со своим уставом, то провинциальным профессионально-замкнутым цехово-ремесленным училищем... Основной тонус университетской жизни был: учись, мысля, исследуя; в консерватории: учись, слушайся, верь на слово, на вкус и не пытай ничего! Дело совсем не в отличии научной исследовательской школы от профессионально-технической, да ещё художественной. Эту естественную разницу учесть было легко. Увы, причины острого различия были глубже - в коренной разнице умственной культуры университета и горделиво замкнувшейся в своей художественно-профессиональной броне консерватории» [2, с. 396].

Узкое понимание своих задач преподавателями консерватории - даже такими выдающимися личностями, как Н.А. Римский-Корсаков, А.К. Глазунов, А.К. Лядов, - приводило к тому, что собственно художественно-творческое развитие учеников фактически оставалось вне сферы внимания и прямого влияния педагогов. Попадавшим в стены консерватории талантливым людям приходилось искать каждому свой путь преодоления господствующих здесь методов обучения.

Творчество Вагнера как раз представляло собой полную противоположность таким тенденциям. Для понимания его произведений недостаточным было иметь музыкальное чутьё и разбираться в технических сторонах музыки. Требовалась напряжённая умственная работа.

Интересно привести в связи с этим наблюдения известного советского музыковеда-теоретика Юрия Николаевича Тюлина о характере творческого дарования, который парадоксальным образом сближал с Вагнером Николая Метнера: «Метнер принадлежал к числу композиторов, которые в высшей степени обладали природной композиторской техникой; ему (как и Шопену, Вагнеру, Глазунову) не нужно было много учиться для 
виртуозного владения ею» [16, с. 112]. В годы овладения теоретическими предметами Вагнер и Метнер одинаково не воспринимали сухих математических расчетов. Так, занимаясь в течение двух лет гармонией с лейпцигским скрипачом К.Г. Мюллером, Вагнер считал эти занятия педантичными и сухими. «Музыка была и оставалась для меня демонским царством, миром мистически возвышенных чудес: все правильное, мне казалось, только уродовало ее. Более соответствующих моим представлениям указаний, чем поучения лейпцигского оркестрового музыканта, я искал в фантастических рассказах Гофмана» [6, с. 47]. Николай Метнер - студент фортепианного факультета Московской консерватории, также всегда подчеркивал, что композиции как таковой никогда не изучал. Гармонию он прошел лишь общую, наравне с другими пианистами. Не вызвавший у него интереса класс контрапункта, который вел не кто-нибудь, а сам всеми уважаемый С.И. Танеев оставил, не проучившись целиком и один семестр. Вместе с тем тот же Танеев высоко ценил проявившееся в произведениях Метнера полифоническое мастерство, а также его органическое чувство формы, как-то в шутку сказав, что Метнер родился с сонатной формой в голове.

Из сказанного становится понятным, что почва для чрезвычайного увлечения Вагнером деятелей русского Серебряного века, к кругу которых принадлежал Эмилий Метнер, была хорошо подготовлена. Вагнер оставался постоянным предметом их размышлений и философского осмысления, рождал аллюзии и отзвуки в художественных произведениях. Им увлечены в этот период А. Скрябин и поздний Н. Римский-Корсаков, а также склонная к смелым новациям группа молодых композиторов. Так, творчество Вагнера сыграло важную роль в формировании художественного мышления Сергея Прокофьева. Подробное знакомство с его произведениями и их анализ помогли юному автору выйти из сферы узко цеховых музыкальных интересов и подготовило к общению с представителями художественной элиты тогдашнего Петербурга ${ }^{6}$. Русское вагнерианство захватило в те годы Вяч. Иванова и А. Блока, А. Белого и В. Брюсова, Н. Реиха и А. Бенуа, сотрудников журнала «Мир искусства».

Большая работа велась над русскими переводами текстов вагнеровских либретто. В 1913 году, когда отмечалось сто-

${ }_{6}^{6}$ Подробнее о роли искусства Вагнера в формировании творчества Прокофьева см. в статье: [19]. 
летие со дня рождения композитора, вышло из печати четырехтомное русское издание произведений Вагнера, в том числе его мемуаров «Моя жизнь». Итоговый характер имела брошюра литературоведа, педагога и религиозного писателя С.М. Дурылина (1886-1954) «Вагнер и Россия. Про Вагнера и будущие пути искусства» [8]. По утверждению автора, Вагнера следует воспринимать как целостное явление мифотворца и мифомыслителя. Миф, созданный народом, Вагнер возвращает народу своим искусством. С. Дурылин пишет про языческие и христианские мотивы вагнеровского мифомышления. Воплощением первых стал, по его словам, образ «лесного мальчика» Зигфрида, не знакомого с существовавшей в обществе системой моральных запретов, действовавшего согласно с собственными естественными побуждениями. По мнению автора брошюры, именно воплощенная в тетралогии «Кольцо нибелунга» языческая стихия нашла наибольший отклик в Германии. В то же время «Парсифаль» и христианский религиозный миф оказался ближе русским последователям. Среди них С. Дурылин упоминает младшего символиста в русской поэзии Вячеслава Иванова (1866-1949), подробно изучавшего религию и культ Диониса. Вяч. Иванов ратовал за создание народного синтетического искусства, основанного на религиозных мифах и мифомышлении. В брошюре С. Дурылина как образец такого мышления подробно описано Сказание про невидимый град Китеж. Интересно, что оперу Н. Римского-Корсакова на данную тему он не считает идеальным воплощением этого сюжета.

Со взглядами С. Дурылина и с его концепцией «Парсифаля» как религиозного мифа полемизирует в новом масштабном исследовании русский филолог и литературовед Михаил Пащенко [12]. По его утверждению, основанному на филологическом методе изучения источников и подкрепленному критической оценкой многих традиционных суждений, «Парсифаль» является образцом истинно христианской мистерии. В биографии самого автора этот последний опус Мастера тесно связан с его поворотом к христианству и к широко понимаемым постулатам христианской веры, преодолевающим конфессиональную ограниченность. Единственным продолжением уникального вагнеровского опыта автор исследования называет произведения Н. РимскогоКорсакова: «Сказание о невидимом граде Китеже и деве Февронии», а затем смеховую мистерию «Золотой петушок». 
Выводы. Прослеживая, как в годы, предшествовавшие Первой мировой войне, в русской культуре воспринимался и адаптировался образ Вагнера, невозможно в заключении хотя бы бегло не вспомнить имя крупнейшего русского поэта Александра Блока. Об интересе к Вагнеру и об основательном знании его трудов свидетельствует факт, что в библиотеке Блока было четырнадцатитомное издание произведений Вагнера, а также русские переводы его работ. Еще в 1900 году своему стихотворению «Валькирия» он дал подзаголовок «на мотив оперы Вагнера». Летом 1909 года в Германии Блок посетил постановку всех частей тетралогии «Кольцо нибелунга», а в 1910 году задумал и в основном завершил поэму «Возмездие». В Пролог поэмы он включил в виде развернутого сравнения ссылку на сюжет вагнеровского «Зигфрида». Наконец, 12 марта 1918 года была написана статья Блока «Искусство и революция», построенная как отклик на одноименную давнюю статью Вагнера. Среди подробностей вагнеровской биографии Блок вспоминает тут общение немецкого композитора с русским анархистом Бакуниным и причастность обоих к революционным событиям, которые разворачивались в Дрездене и привели к майскому восстанию 1849 года. Несмотря на дальнейший отход Вагнера от революционных идей его искусство, по мнению Блока, не лишилось подлинно революционного духа.

Первая мировая война, которая разделила Россию и Германию как воюющие стороны, началась на кульминационной точке русского вагнеризма. Новая актуализация творчества и фигуры Вагнера наступит в годы после революции. Но это уже совсем другая история. А уникальная рецепция деятелями русской культуры конца XIX, начала XX века наследия Рихарда Вагнера как композитора, поэта, теоретика искусства стала неотъемлемой частью этого культурного контекста и источником вдохновения для литераторов, художников, музыкантов. По-своему она затронула и творчество двух ярких представителей этой эпохи - Эмилия и Николая Метнеров.

\section{СПИСОК ЛИТЕРАТУРЫ}

1. Андрей Белый и Эмилий Метнер. Переписка. 1902-1915. ООО «Новое литературное обозрение». 2017. 736 с.

2. Воспоминания о Б.В. Асафьеве. Ленинград : Музыка, 1974. $510 \mathrm{c}$. 
3. Браудо Е.М. Рихард Вагнер и Россия. (Новые материалы и его биография). Культурно-просветительское кооперативное товарищество «Начатки знания», Петроград, 1923. 46 с.

4. Богданова И. Ріхард Вагнер та італійська опера останньої третини XIX ст. Часопис НМАУ імені П.І. Чайковського: Науковий журнал НМАУ ім. П.І. Чайковського. Київ : Національна музична академія України ім. П.І. Чайковського. 2013. № 2(19). С. 33-44.

5. Богоявленский С. Итальянская музыка первой половины XX века. Ленинград : Музыка, 1986. 144 с.

6. Вагнер Р. Моя жизнь. Москва : Изд-во Экмо; СанктПетербург : Изд-во Terra Fantastica, 2003. С. 47.

7. Гозенпуд А.Р. Вагнер и русская культура. Ленинград, 1992. 294 с.

8. Дурылин С. Рихард Вагнер и Россия. О Вагнере и будущих путях искусства. Москва, 1913. 70 с.

9. Кондаков И., Корж Ю. Рихард Вагнер в русской культуре Серебряного века. Общественные науки и современность. 1996. № 1. C. 160 .

10. Корж Ю.В. «Дух музыки» в философии культуры русского символизма, автореферат на соискание ученой степени кандидата культ урологии. Москва, 2005.

11. Метнер Н.К. Статьи. Материалы. Воспоминания. «Советский композитор». Москва. 1981. 362 с.

12. Пащенко М. Сюжет для мистерии: Парсифаль - Китеж Золотой Петушок (историческая поэтика оперы в канун модерна). Москва, Санкт-Петербург : Центр гуманитарных инициатив. 2018. $720 \mathrm{c}$.

13. Поль В. Фрагменты воспоминаний. Н.К. Метнер. Статьи. Материалы. Воспоминания. Москва : «Советский композитор», 1981, комментарии 3.А. Апетян. С. 318.

14. Русская музыкальная газета. Санкт-Петербург. 1897. № 12. C. 1695 .

15. Соловьев В. С. Соч. в 2-х томах. Т. 2. Москва, 1988.

16. Тюлин Ю.Н. Встречи с Н.К. Метнером. Н.К. Метнер. Статьи. Материалы. Воспоминания. "Советский композитор». Москва, 1981. Комментарии 3.А. Апетян. С. 112.

17. Чайковский П.И. Байрейтское музыкальное торжество. П.И. Чайковский. Музыкально-критические статьи. Москва : Музгиз, 1953. С. 302.

18. Черкашина М. Александр Николаевич Серов. Москва : Музыка, 1985. 162 с.

19. Черкашина М. Немецкий мастер как учитель Прокофьева. Музыкальная академия. 1994. № 3.

20. Черкашина М. Вагнеровский фестиваль в Байройте: страницы истории. Материалы международной научно-практической конференции «IV Серебряковские чтения». Кн. 1. Музыковедение, философия искусства / Редкол. : Е.В. Смагина и др. Волгоград : Изд-во ВолГУ, 2007. C. $27-55$. 
21. Черкашина М. Фрідріх Ніцше - філософ і музикант. Науковий вісник Національної музичної академії України імені П.І. Чайковського. Вип. 12: Історія музики в минулому і сучасності. Київ, 2000. С. 228-240.

22. Шюре Э. Рихард Вагнер и его музыкальная драма. Перевод с последнего французского издания с согласия автора баронессы Н.М. Розен. Издание т-ва М. О. Вольф, С. Петербург, Москва. 1909. $312 \mathrm{c}$.

\section{REFERENCES}

1. Andrei Bely and Emilius Metner (2017). Correspondence. 19021915. LLC "New Literary Review" [in Russian].

2. Memories of B. V. Asafiev. (1974). L.: Music [in Russian].

3. Braudo, E. M. (1923). Richard Wagner and Russia. (New materials and his biography). Cultural and educational cooperative partnership "The Beginners of Knowledge", Petrograd [in Russian].

4. Bogdanova, I. (2013). Richard Wagner and the Italian opera of the last third of the nineteenth century // Journal of the PI Tchaikovsky National Academy of Science: Scientific Journal of the National Academy of Sciences of Ukraine. Tchaikovsky. K.: National Music Academy of Ukraine. Tchaikovsky. №2 (19). P. 33-44 [in Ukrainian].

5. Bogoyavlenskiy, C. (1986). Italian music of the first half of the twentieth century. Leningrad: Music [in Russian].

6. Wagner, R. (2003). My life. M.: Ekmo Publishing House; St. Petersburg: Publishing House Terra Fantastica, P. 47 [in Russian].

7. Gosenpud, A. (1913). R. Wagner and Russian culture. L. 1992 [in Russian].

8. Durylin S. Richard Wagner and Russia. About Wagner and the future paths of art. Moscow [in Russian].

9. Kondakov, I., Korzh, Yu. (1996). V. Richard Wagner in Russian culture of the Silver Age // Social Sciences and the Present, No. 1. P. 160 [in Russian].

10. Korzh, Yu. (2005). "The Spirit of Music" in the philosophy of culture of Russian symbolism, abstract on the degree of candidate of cult urology. Moscow [in Russian].

11. Metner, N.K. (1981). Articles. Materials Memories. "Soviet composer." Moscow [in Russian].

12. Pashchenko, M. (2018). The plot for the mystery: Parsifal Kitezh - The Golden Cockerel (historical poetics of the opera on the eve of modernity). Moscow; $\mathrm{SPb}$.: Center for Humanitarian Initiatives [in Russian].

13. Paul, V. (1981). Fragments of memories // N.K. Metner. Articles. Materials Memories. Moscow, "Soviet composer". Comments by Z. A. Apetian. P. 318 [in Russian].

14. Russian musical newspaper (1897). St. Petersburg, No. 12. P. 1695 [in Russian].

15. Soloviev, V.S. (1988). Soch. in 2 volumes. T. 2. Moscow [in Russian]. 
16. Tyulin, Yu. (1981). Meetings with N. K. Metner // N.K. Metner. Articles. Materials Memories. Moscow, "Soviet composer". Comments by Z. A. Apetian. P. 112 [in Russian].

17. Tchaikovsky, P.I. (1953). Bayreuth musical celebration // P.I. Tchaikovsky. Musically critical articles. Moscow: Muzgiz, P. 302 [in Russian].

18. Cherkashina, M. (1985). Alexander Nikolaevich Serov. Moscow, Music [in Russian].

19. Cherkashina, M. (1994). German master as a teacher of Prokofiev // Music Academy. No. 3 [in Russian].

20. Cherkashina, M. (2007). Wagner Festival in Bayreuth: pages of history // Materials of the international scientific-practical conference "IV Serebryakov readings". Prince 1. Musicology, philosophy of art. Editorial board: E. V. Smagina and others. Volgograd: VolSU Publishing House, P. 27-55 [in Russian].

21. Cherkashina, M. (2000). Friedrich Nietzsche - philosopher and musician // Scientific Bulletin of the National Music Academy of Ukraine named after PI Tchaikovsky. No. 12: History of music in the past and present. Kyiv. P. 228-240 [in Russian].

22. Schure, E. (1909). Richard Wagner and his musical drama. Translation from the last French edition with the consent of the author of the Baroness N. M. Rosen. Edition t-va M.O. Wolf, S. Petersburg, Moscow [in Russian]. 